\title{
Impact of Abradant Size on Damaged Zone of 304 AISI Steel Characterized by Positron Annihilation Spectroscopy
}

\author{
P. HORODEK, K. SIEMEK, J. DRYZEK, and M. WRÓBEL \\ Positron annihilation, electron microscopy, and optical profilometry studies of steel 304 AISI \\ exposed to blasting with different size of abradant, i.e., alumina and glass have been reported. \\ The size of abradant particles has a direct impact on the roughness which changed from $0.7 \mu \mathrm{m}$ \\ to about $5 \mu \mathrm{m}$. Positron lifetime measurements revealed the existence of defects associated with \\ the dislocations in samples processed with a smaller medium. In the case of blasting with \\ aluminum oxide particles with a diameter of $250 \mu \mathrm{m}$, monovacancies were detected in processed \\ specimens. The defect concentration induced by blasting decreases with the increase of the depth \\ from the surface, and it depends on the abradant particles' size.
}

https://doi.org/10.1007/s11661-018-5067-4

(c) The Author(s) 2018

\section{INTRODUCTION}

BLASTING is a surface treatment process (STP) useful in a wide spectrum of applications. The abrasive particles in the stream of compressed air leave the nozzle and hit material interacting with a surface. This process is often applied in the cleaning of industrial objects such as boat hulls, bridges, parts of machines, and cars to remove corrosion and achieve expected roughness of denture at the preliminary stage. Blasting makes it possible to treat complicated shapes with areas unreachable by polishing. Hence, it has found application in stomatology to excise deposits on teeth and discolorations.

In addition to altering the surface, blasting also introduces changes in the near-surface region creating the damage region called a subsurface zone. This zone contains plastic layers and elastic deformations which modify its microstructure properties. ${ }^{[1]}$ As a result, the local disorders as well as cracks can be generated leading to wear and debris generation. Impact of a given type of STP on the subsurface zone and its evolution beneath the worn surface is still an active research problem in the field of material engineering. This kind of investigation of the subsurface zone is usually performed using conventional engineering methods e.g., microhardness

P. HORODEK, K. SIEMEK, and J. DRYZEK are with the Institute of Nuclear Physics Polish Academy of Sciences, 31342 Kraków, Poland. Contact e-mail: pawel.horodek@ifj.edu.pl M. WRÓBEL is with the AGH University of Science and Technology, 30 Mickiewicza Ave., 30-059 Kraków, Poland.

Manuscript submitted April 12, 2018.

Article published online December 12, 2018 tests $^{[2]}$ and other analytical techniques like Transmission Electron Microscopy (TEM), Scanning Electron Microscopy (SEM), and X-Ray Diffraction (XRD). However, some changes causing the generation of lattice defects occur also at the atomic level. Their presence is hardly observed by the mentioned methods.

Positron annihilation spectroscopy (PAS) is a sensitive tool for detection of open-volume defects such as vacancies, their clusters, dislocations, nano-voids, etc. PAS techniques deliver information about the kind of defects, their size and concentration. The successful application of this method to studies of subsurface zone has been proven in numerous studies. ${ }^{[3]}$

Blasting can be characterized by many parameters such as angle, pressure, size, or type of abrasive particles and process duration. Thus, changes generated on and below the surface can be strongly dependent on these features. It should be also mentioned that blasting is a popular STP leading to nanocrystallization. ${ }^{[5]}$ Treated material is subsequently annealed and the produced nano-size grains improve surface properties. Introduced dislocations are the basis of this process. ${ }^{[6]}$ Hence, the above can be regarded as the additional field of blasting application.

304 AISI stainless steel was chosen as the object of studies because it is a very popular material in industry, and also an alloy common in research. Their properties strongly depend on the presence of plastic deformation e.g., austenitic (fcc) structure can be transformed to martensitic (bcc) phase. ${ }^{[7]}$ Moreover, blasting is often applied in order to increase the corrosion resistance of steel by generation of nanocrystallization. ${ }^{[8]}$ On this basis, the chosen material is found to be convenient from both theoretical and practical points of view. 
In this paper, the impact of the particle size on the subsurface zone in blasted 304 AISI steel observed by PAS and complementary methods is reported. This is the continuation of our previous works related to the influence of blasting angle on the properties of subsurface zone in the same kind of material. ${ }^{[4]}$

\section{EXPERIMENTAL DETAILS}

\section{A. Sample Preparation}

Stainless steel 304 AISI discs of $5 \mathrm{~mm}$ thick and 10 $\mathrm{mm}$ in diameter with following chemical composition: 0.06 pct $\mathrm{C}, 1.0$ pct Si, 2.0 pet $\mathrm{Mn}, 0.043$ pet $\mathrm{P}, 0.015$ pct $\mathrm{S}, 0.1$ pet $\mathrm{N}, 17$ pet $\mathrm{Cr}$, and 10 pet $\mathrm{Ni}$ were studied. Firstly, all of them were annealed at $1000{ }^{\circ} \mathrm{C}$ for 4 hours in vacuum conditions of $10^{-5}$ Torr. Then, they were slowly cooled down in a closed furnace to room temperature. In this way, samples were brought down to the same bulk state and contained only residual defects. One disc was saved as a reference, second for sequential pressing, while others were exposed to blasting.

Blasting was performed using Renfert Vario Basic Jet blaster in 60 seconds under the pressure of 5 bar in the distance of $10 \mathrm{~mm}$ between the surface and a perpendicularly directed nozzle. Three samples were exposed to blasting using Edelkorund abradant containing 99.8 pct aluminum oxide (alumina) of different size: 50, 110, and $250 \mu \mathrm{m}$. Additional specimen was treated using $125-\mu \mathrm{m}$ glass beads distributed by ERNST HINRICHS GmbH. The microscopic pictures of alumina particles and glass balls are shown in Figure 1. The second type of abradant is characterized by more regular shape in comparison to the first one.

\section{B. Experiment Description}

Complementary studies involving surface characterization with the use Hitachi S-3500N SEM and optical profiler WYKO NT9300 (Veeco) were carried out.

In the case of PAS studies, two experimental techniques were applied. Firstly, positron lifetime (LT) was measured directly on the blasted surfaces. The spectrometer based on the $\mathrm{BaF}_{2}$ scintillators was employed. Its timing resolution equaled $250 \mathrm{ps}$. During

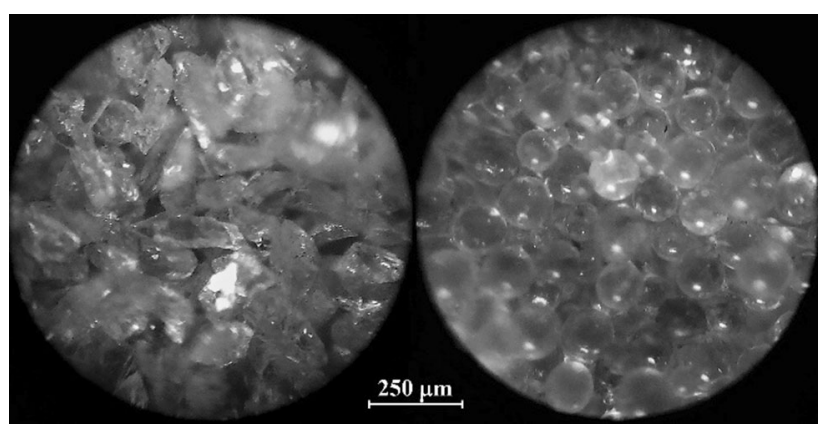

Fig. 1-Shapes of alumina particles (on left) and glass balls (on right) used in studies in 180 magnification. experiments, the isotope $22-\mathrm{Na}$ with activity of $32 \mu \mathrm{Ci}$ enveloped into two $7-\mu \mathrm{m}$-thick kapton foils was always placed between two samples. The total number of counts in collected spectra was about $10^{6}$. The deconvolution procedure performed with LT code $\mathrm{e}^{[9]}$ took into account the positron source correction.

The observation of the Doppler broadening (DB) of the annihilation line was the second realized PAS method. The 22-Na isotope with activity $15 \mu \mathrm{Ci}$ hidden in a copper capsule with a titanium window $5 \mathrm{~mm}$ in diameter and $7 \mu \mathrm{m}$ thick was used as a positron source. The capsule with the window directed to the top was set in front of the detector. Then, during the measurement, the window was directed to the surface of the tested sample. In this case, the positrons emitted from the source passed through the window and then were inserted into the sample. Annihilation quantum was then registered with $\mathrm{HPGe}$ detector with $1.20 \mathrm{keV}$ resolution for energy $511 \mathrm{keV}$. In this way, we detected photons both from the sample as well as from the copper capsule. However, the participation of annihilation in the source was always the same and any changes in the observed characteristics could come only from the sample. The obtained spectra contained $2 \times 10^{6}$ counts in $511 \mathrm{keV}$ line. More details on the experimental setup were given in Reference 10.

\section{RESULTS AND DISCUSSION}

\section{A. The Surface Characterization}

SEM micrographs and optical profiles of the studied samples are shown on the left and right side of Figure 2, respectively. In both cases, a significant impact of the size and kind of blasting media is observed. The reference surface is rather smooth with marked grain boundaries being the result of annealing, i.e., mainly recrystallization. Blasting decorates these surfaces by changing their roughness, perceived qualitatively as the increase with the growth of the dimension of alumina particles. However, surface processed by glass balls seems to diverge from this tendency in the SEM micrographs. The bigger size of alumina abradant causes well-marked tracks in the shape of sharp edges. This is not visible in the surface modified by glass balls which is characterized by a rather smooth morphology with a small number of edges. The optical profiles do not reveal this observation. Surface exposed to blasting shows the existence of certain types of peaks and valleys that are more distinguished for bigger size of abrasive particles.

Additionally, the optical profiles provide quantitative information achieved by determination of the average roughness values $R_{\mathrm{a}}$. The $R_{\mathrm{a}}$ is defined as the arithmetic mean of the absolute values of the surface departures from the mean plane. This is the most representative parameter for surface characterization. The corresponding values are displayed in Table I.

The average roughness achieves the lowest value for reference sample. The impact of blasting exhibits increasing $R_{\mathrm{a}}$ values. The growth of roughness with 


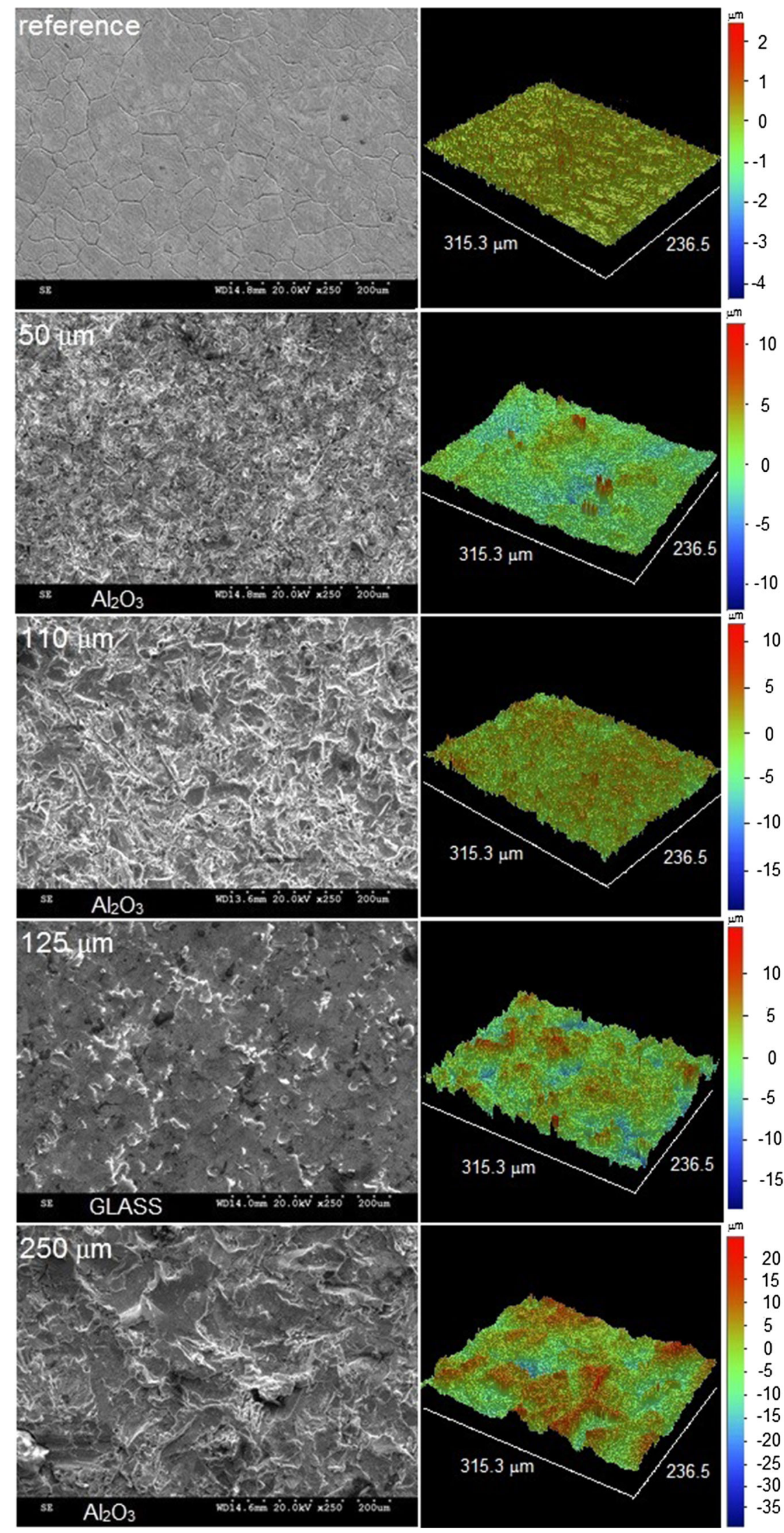

Fig. 2-SEM micrographs (on the left) and optical profiler images (on the right) for samples 304 AISI stainless steel exposed to blasting with various size of abrasive particles. 
Table I. Values of Average Roughness for Studied Samples

\begin{tabular}{lc}
\hline Sample & $R_{\mathrm{a}}(\mu \mathrm{m})$ \\
\hline Reference & 0.77 \\
Alumina-50 $\mu \mathrm{m}$ & 2.57 \\
Alumina-110 $\mathrm{m}$ & 3.14 \\
Glass $-125 \mu \mathrm{m}$ & 2.14 \\
Alumina-250 $\mu \mathrm{m}$ & 5.12 \\
\hline
\end{tabular}

the size of the abrasive particles is strongly noticed for alumina media. This tendency is broken by the value $2.14 \mu \mathrm{m}$ obtained for glass balls which is lower in comparison to the smallest size of alumina. It can be explained by the shape of the glass balls, which is more regular. A larger area during the contact of the hitting particles with the surface generates more smooth changes in the roughness in comparison to the irregular and sharp alumina particles. For this reason, influence of media size should be realized within the same kind of abrasive material. The impact of the chemical composition, related to the hardness of particles also cannot be excluded.

\section{B. The LT Measurements}

Positron lifetime measurements were performed directly on the worn surfaces. The main signal comes from the depth of $29 \mu \mathrm{m}$ where about 63 pct of primary emitted positrons annihilate. The values of positron lifetimes obtained for all studied samples are collected in Table II. Only one lifetime component was found in the deconvoluted spectra. In the case of the reference sample, the value of $106 \pm 1 \mathrm{ps}$ is in a perfect agreement with the value of positron lifetime reported for undamaged crystalline structure of steel. ${ }^{[12]}$ Obtained positron lifetimes for blasted samples are between 158 and 174 ps. Similar values have been observed in the studied type of stainless steel exposed to different surface processing as sliding under various load, ${ }^{[13]}$ cutting with various methods, ${ }^{[12]}$ and blasting. ${ }^{[4]}$ The sample treated with the biggest particle size applied in these investigations is characterized by positron lifetime equal to 174 ps. This value determines the occurrence of monovacancies. ${ }^{[14]}$ In turn, positron lifetimes for the rest of the treated samples are lower and vary in the range of 158 to 166 ps. These are in good agreement with lifetimes representing positron trapping at dislocations reported for $\mathrm{Fe}^{[15]}$ and stainless steel. ${ }^{[16,17]}$ However, values achieved in this case are lower in comparison to lifetimes for single vacancies in $\mathrm{Fe}$ and higher than for dislocations (130 to $150 \mathrm{ps}$ ) obtained by Hori et al. ${ }^{[14]}$ This discrepancy was discussed earlier by Cížek et al. ${ }^{[18]}$ on the basis of two-stage trapping model given by Smedskjaer et al. ${ }^{[19]}$ According to the cited contemplation, positron can move along the dislocation line to the vacancy linked to dislocation, or the jog at the dislocation line where it can annihilate. The elastic stress field originating from dislocation compresses the vacancy adjoined to this region. As a result, positron lifetime
Table II. The Values of the Positron Lifetime Measured Directly on the Blasted Surface for Samples 304 AISI Sizes

\begin{tabular}{lc}
\hline Sample & $\tau(\mathrm{ps})$ \\
\hline Reference & $106 \pm 1$ \\
Alumina-50 $\mathrm{m}$ & $166 \pm 1$ \\
Alumina-110 $\mathrm{m}$ & $165 \pm 1$ \\
Glass $-125 \mu \mathrm{m}$ & $158 \pm 1$ \\
Alumina-250 $\mathrm{m}$ & $174 \pm 1$ \\
\hline
\end{tabular}

coming from the annihilation at the vacancy near the dislocation line can be lower in comparison to the isolated one. Moreover, various atomic relaxations in the surrounding of screw and edge dislocations are reflected in different positron lifetimes. For example, Park et al. ${ }^{[15]}$ distinguished positron lifetime equal to 142 ps for annihilation at screw and 165 ps for edge dislocation. The medium values between these two kinds of defects point out annihilation at their mixture. It could suggest that positron lifetimes obtained in our studies reflect the presence of screw dislocations in the samples blasted with $50,110 \mu \mathrm{m}$ alumina, and also screw dislocations with some fraction of edge ones for the glass ball-treated targets. Of course, in the nearest vicinity of those dislocations, the attributed vacancies are present. However, results reported by Hidalgo et al., ${ }^{[20]}$ performed for deformed $\mathrm{Fe}$, warn about recognizing the type of dislocations. They claim that above $240 \mathrm{~K}$, the type of dislocations become unstable and suggest to identify similar lifetime values as positron trapping in defects associated with the dislocations.

Thus, layers appearing in the zone adjoined to the surface are significantly damaged. In order to find out how big the damage is in deeper regions, other measurements must be performed.

\section{The Defects Depth Profiles}

The depth distribution of defects generated by blasting has been determined in the chemical etching experiment. As mentioned above, the mean depth of positrons implanted directly from the $22-\mathrm{Na}$ source into steel equals ca. $29 \mu \mathrm{m}$. It indicates that about 63 pct of positrons annihilate at this depth from the entrance surface. In order to obtain information from much deeper regions, the special approach realized by sequential etching is necessary. Thus, after each measurement, samples were etched in hydrofluoric acid-based paste to reduce their thickness. This was measured using digital micro screw with accuracy $\pm 1 \mu \mathrm{m}$. The layer of about a few micrometers was removed each time and DB spectrum was recorded.

The analysis of the obtained spectra was reduced to extraction of the $\mathrm{S}$ parameter from the shape of the annihilation line. It is defined as a ratio of the area below the central part of the annihilation line to the 
total area marked by the peak. Its value reflects the fraction of positron annihilation with low momentum electrons mainly present in defects. This parameter is very sensitive to defects concentration and its value increases with the increasing concentration. ${ }^{[21]}$ The obtained dependencies are presented in Figure 3 in the form of $\mathrm{S}$ parameter in dependency of the etched depth. The so-called "bulk" marking the S parameter value obtained for the reference sample is tagged as the hatched area in this figure. In this case, the constant level is understood by the presence of only residual defects and the fact that etching does not cause additional damage in the structure. Higher values of the $S$ parameter near the surface characterize profiles for the processed samples. It proves the existence of structural defects introduced by blasting. The distribution obtained for the sample treated using alumina particles with the smallest size and the $S$ parameter decreases linearly with the depth in the whole modified layer. The thickness of the defected layer is appointed by the depth for which the $\mathrm{S}$ parameter from the blasted sample achieves value as in the "bulk" region. In this way, the thickness of the damaged zones increases with the size of the abrasive particles. The decrease of the values of $S$ parameter with the etched thickness can be interpreted as the decrease of the defect concentration. The linear tendency appears in other profiles; however, it is present after the layer marked by "plateau" near the entrance surface. This is surprising and was not observed in the samples of the same kind of stainless steel exposed to blasting with $50 \mu \mathrm{m}$-alumina and different angles. ${ }^{[4]}$ The thickness characterized by a constant level of $\mathrm{S}$ parameter grows with the size of the abrasive particles. For $110 \mu \mathrm{m}$ media it is close to $15 \mu \mathrm{m}$, in the case of $125-\mu \mathrm{m}$ glass balls equals $20 \mu \mathrm{m}$, and finally a layer of ca. $60 \mu \mathrm{m}$ appears after processing using $250 \mu \mathrm{m}$-alumina.

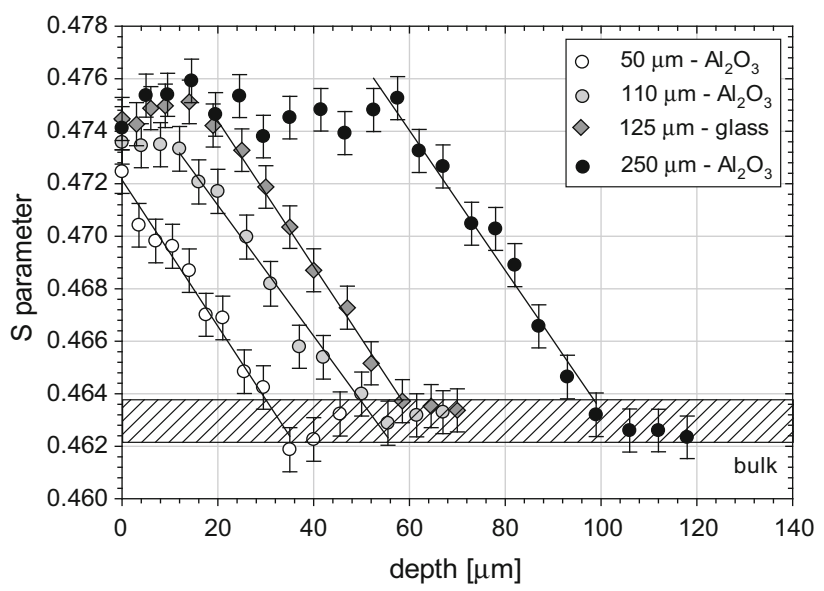

Fig. 3-Dependency of the S parameter on the depth below the surface for the 304 AISI stainless steel samples blasted with various sizes of abrasive particles. The hatched region represents the bulk value of the $\mathrm{S}$ parameter obtained for the well-annealed reference sample.
"Plateau" revealed in three blasted samples is an unexpected observation which requires wider discussion. There are three possible sources of it. First, positron annihilation could take place in the layer of abrasive particles stopped in the surface. Some parts of abradant were visible in SEM pictures under bigger magnification, but their quantity was vestigial and approximate size definitely smaller in comparison to the thickness of the "plateau." Moreover, some signal should have been registered in the form of additional lifetime component coming from annihilations in the abrasive media. This was observed in the case of copper exposed to sandblasting, where the abrasive particles were embedded at the depth of about $50 \mu \mathrm{m}$. $^{[17}$

Another explanation of the S parameter "plateau" could indicate the existence of a special layer with the constant defect concentration. This could be a nanocrystallized layer caused by blasting, where grain boundaries may serve as defect sinks. However, the creation of a nanocrystallized layer with blasting should be supported by annealing process as it was pointed in References 6 and 8. The surface treatment leads to the development of high-density dislocations being then rearranged by heating. ${ }^{[22,23]}$ However, the annealing after blasting was not performed for samples studied here. In the case of specimen treated with $250 \mu \mathrm{m}$ particles (where "plateau" is the biggest), the positron lifetime pointed out the presence of monovacancies. During blasting, no temperature increase was observed. In 304L stainless steel reduced to $40 \mathrm{pct}$ cross-section, the recrystallization starts after $20 \mathrm{~min}-$ utes of annealing at $650{ }^{\circ} \mathrm{C}$ to $700{ }^{\circ} \mathrm{C}$, while recrystallization from 50 pct reduction also requires 20 minutes of annealing at $750{ }^{\circ} \mathrm{C}$ to $800{ }^{\circ} \mathrm{C} .{ }^{[24]}$ Recrystallization is proceeded by recovery. ${ }^{[25]}$ In turn, recovery begins from changes in the distribution of the most mobile lattice defects like vacancies and interstitial atoms. ${ }^{[26]} \mathrm{A}$ decrease of the defects concentration, with a higher density in a deformed state than in equilibrium, takes place. ${ }^{[27]}$ The recovery temperature for vacancies in 304 stainless steel is about $300^{\circ} \mathrm{C} .{ }^{[28]}$ The existence of monovacancies in the case of sample treated with $250 \mu \mathrm{m}$ particles allows us to conclude that a significant degree of recovery did not occur. To sum up, it would be risky to connect the "plateau" with a nanocrystallized layer, as the temperatures required for it were not achieved during blasting. They were also not delivered to the rearranged defects after the treatment. Additionally, as has been repeatedly shown, the presence of the nanocrystallized layer affects certain properties of the material, such as the mechanical behavior and can be a few dozen micrometers thick but it is not homogenous. ${ }^{[8]}$ For example, reported microhardness tests show fast decrease from the surface to the inside.

We concur with the explanation that the mentioned "plateau" points out the upper limit of sensibility of the PAS methods for reflection of defect concentration. Strong plastic deformation inflicted on blasting introduced defects in the amount that traps all the implanted positrons. In this way, the higher defect concentration which overloads the sensitivity of PAS is visible as a 
"plateau" breaking the linear dependence of the profile. In order to confirm this assumption, an auxiliary (supplement) experiment was considered. A well-annealed sample was sequentially pressed to compress its thickness which was evaluated in each step. The DB measurement was performed, results of which are depicted in Figure 4. The $\mathrm{S}$ parameter value goes up with the thickness reduction and achieves saturation around 13 pet of compression. Similar trend was observed in other metals such as $\mathrm{Ag}, \mathrm{Au}$, and Fe. ${ }^{[29]}$ The following formula was used to described the measured points

$$
S=S_{\text {def }}+\left(S_{\text {bulk }}-S_{\text {def }}\right) \exp (-c \varepsilon),
$$

where $\varepsilon$ is the thickness reduction in percent, and $c$ is an adjustable parameter. The best fit is presented with a solid black line in Figure 4. As a result, the following parameters were obtained: $S_{\text {def }}=0.474(1)$, $S_{\text {bulk }}=0.462(1)$, and $c=0.21(1)$. The value of $S_{\text {def }}$ coincides with the $\mathrm{S}$ parameter of the "plateau" observed in Figure 3 and determines the upper limit for the detection changes in defects concentration. It can also be concluded that the plastic deformations created in samples on the areas marked by the $\mathrm{S}$ parameter saturation are comparable to these produced by pressing after 10 pct thickness reduction.

Taking into account that positrons are localized in single vacancies, the limit of defect concentration $c_{v}$ can be estimated by application of the below formula ${ }^{[31]}$ to the results obtained in the sequential pressing

$$
c_{v}=\frac{S-S_{\mathrm{bulk}}}{\mu \tau_{\mathrm{bulk}}\left(S_{\mathrm{def}}-S\right)} .
$$

Here $\tau_{\text {bulk }}$ is the positron lifetime in the defect-free bulk (Table I), $S_{\mathrm{def}}$ is the $\mathrm{S}$ parameter measured in the case of

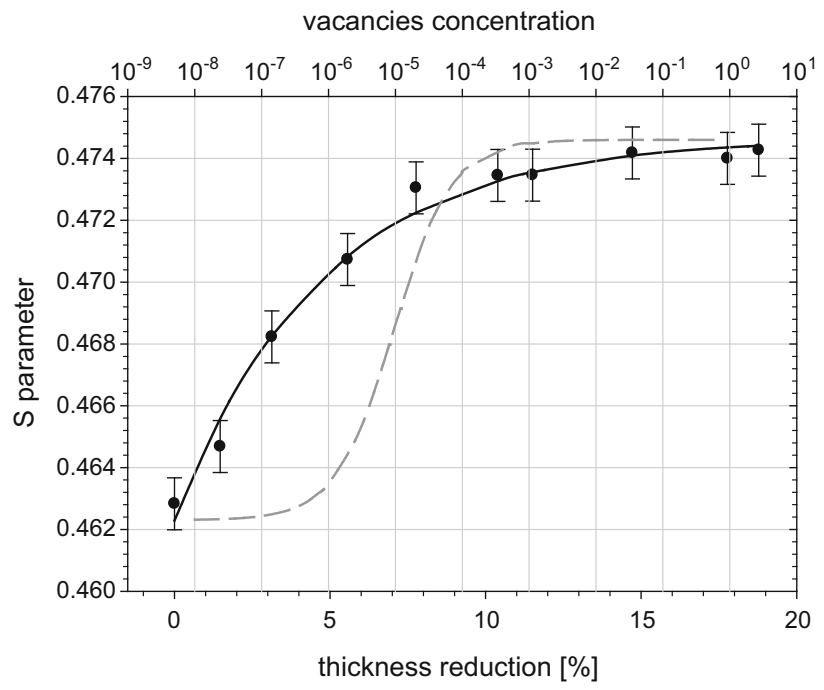

Fig. 4-The dependency of the measured $S$ parameter on the thickness reduction (bottom) of the well-annealed 304 AISI sample exposed to compression. Black solid line represents the best fit of measured points using Eq. [1]. Gray drop curve shows S parameter $v s$ estimated vacancies concentration calculated on the basis of Eq. [2]. annihilation in defect, $S_{\text {bulk }}$ means $\mathrm{S}$ parameter for defect-free structure, and $\mu$ is positron trapping coefficient specific for the given type of material and defect. For single vacancy in Fe, it equals $1.1 \times 10^{15} \mathrm{~s}^{-1}$.332] The estimated concentration in function of thickness compression has been shown with a dashed gray line in Figure 4. The curve saturates for concentration around $10^{-3}$ which means that in the "plateau" observed in Figure 3 this limit was achieved with sandblasting.

It should be emphasized that the auxiliary experiment was performed to point out the limit of PAS sensitivity by evaluation of the maximal value of $S$ parameter and its connection with defect concentration. It was done by compression of an additional sample. The character of plastic deformation between pressing and blasting is different because, e.g., the strain rate, must vary with loading conditions. However, sooner or later, the same kind of material exposed to plastic deformation achieves the level of defect concentration that is too big to be detected by PAS. For example, the strain rate during compression caused by various loading conditions does not move this range but can change the parameters within which it will be reached.

For this reason, we accept that for the sample exposed to blasting with the alumina particles of size $250 \mu \mathrm{m}$, level of strain up to the depth of about $60 \mu \mathrm{m}$ is higher than 10 pct, see Figure 3. Similarly, for samples blasted with glass balls of $125 \mu \mathrm{m}$ in diameter, the thickness of the layer with this strain is lower, i.e., $20 \mu \mathrm{m}$, only. At higher depths the strain gets lower. For other samples, the strain across the depth is lower than 10 pct.

The decreasing parts of the $\mathrm{S}$ parameters profiles presented in Figure 3 were fitted using linear function $S=a z+b$, where $z$ represents the depth. Both adjustable parameters, i.e., the slope and intercept are gathered in Table III. It should be highlighted that both the slope and the intercept remain almost constant for all samples. However, the total thickness of the damaged layer significantly increases with the size of the applied abradant, see last column in Table III and Figure 3. The lowest thickness was estimated to be about $35 \mu \mathrm{m}$, for $50 \mu \mathrm{m}$ alumina, and $100 \mu \mathrm{m}$ for the biggest abrasive particles. The agreement with our previous results for the range of defects in a sample treated with $50 \mu \mathrm{m}$ alumina was achieved. ${ }^{[4]}$ It also should be mentioned that the estimated layers are much smaller in comparison to the damaged zones appointed for the same kind of steel exposed to dry sliding. ${ }^{[13]}$ However, shorter defected thicknesses produced by blasting can be

Table III. The Values of the Slope $a$ and Intercept $b$ of the Fitted Straight Lines in Fig. 3 and the Total Depth of Damaged Layer for Different Samples

\begin{tabular}{lccc}
\hline Sample & $\begin{array}{c}\text { Slope } a \\
\left(\mu \mathrm{m}^{-1}\right)\end{array}$ & $\begin{array}{c}\text { Intercept } \\
b\end{array}$ & $\begin{array}{c}\text { Total Depth } \\
(\mu \mathrm{m})\end{array}$ \\
\hline Alumina-50 $\mu \mathrm{m}$ & $0.0003(1)$ & $0.47(1)$ & 35 \\
Alumina-110 $\mu \mathrm{m}$ & $0.0002(1)$ & $0.48(1)$ & 50 \\
Glass-125 $\mu \mathrm{m}$ & $0.0003(1)$ & $0.48(1)$ & 60 \\
Alumina-250 $\mu \mathrm{m}$ & $0.0003(1)$ & $0.48(1)$ & 100 \\
\hline
\end{tabular}


occupied by much higher defects concentration than in the case of sliding.

\section{CONCLUSIONS}

The main conclusion obtained from the performed studies is that the abradant size used in blasting of the 304 AISI stainless steel has the direct impact on the changes generated on the surface and below it. In particular,

1. the surface roughness increases with abradant size;

2. blasting using abradant with the size up to $125 \mu \mathrm{m}$ generates defects associated with dislocations while treatment with $250 \mu \mathrm{m}$ particles creates monovacancies;

3. the total thickness of the damaged layer increases with the size of abradant; and

4. the thickness of the observed "plateau" depends on the size of abradant, the highest thickness, i.e., $60 \mu \mathrm{m}$ was obtained for a sample blasted with the $250 \mu \mathrm{m}$ alumina. In the zone of "plateau," the strain level induced by blasting is higher than 10 pct.

\section{OPEN ACCESS}

This article is distributed under the terms of the Creative Commons Attribution 4.0 International License (http://creativecommons.org/licenses/by/4.0/), which permits unrestricted use, distribution, and reproduction in any medium, provided you give appropriate credit to the original author(s) and the source, provide a link to the Creative Commons license, and indicate if changes were made.

\section{REFERENCES}

1. S. Rice, H. Nowotny, and S. Wayle: Key Eng. Mater., 1989, vol. 33, pp. 77-100.

2. A. Haseeb, M.A. Islam, and M.M.A. Bepari: Wear, 2000, vol. 244, pp. 15-19.

3. E. Dryzek: J. Mater. Sci., 2003, vol. 38, pp. 3755-63.

4. P. Horodek, K. Siemek, J. Dryzek, A.G. Kobets, and M. Wróbel: Tribol. Lett., 2017, vol. 65 (30), pp. 1-7.
5. M.R. Belbasi and M. Ramezani: Mater. Phys. Mech., 2013, vol. 17 , pp. 33-37.

6. S.B. Fard and M. Guagliano: Frattura Integr. Strutt., 2009, vol. 7, pp. 3-16.

7. L.P. Bendel, F.G. Shellock, and M. Steckel: J. Magn. Reson. Imaging, 1997, vol. 7, pp. 1170-73.

8. X.Y. Wang and D.Y. Li: Wear, 2003, vol. 255, pp. 836-45.

9. J. Kansy: Nucl. Instrum. Methods Phys. Res. A, 1996, vol. 374, pp. 235-44.

10. P. Horodek and J. Dryzek: Acta Phys. Pol. B Proc. Suppl., 2016, vol. 9, pp. 1001-07.

11. J. Dryzek and D. Singleton: Nucl. Instrum. Methods Phys. Res. B, 2006, vol. 252, pp. 197-204.

12. P. Horodek, J. Dryzek, and M. Wróbel: Trobol. Lett., 2012, vol. 45, pp. 341-47.

13. J. Dryzek, P. Horodek, and M. Wróbel: Wear, 2012, vols. 294-295, pp. 264-69.

14. K. Hori, K. Koike, and R. Oshima: Appl. Surf. Sci., 2005, vol. 242, pp. 304-12.

15. Y.K. Park, J.T. Waber, M. Meshii, C.L. Snead, and C.G. Park: Phys. Rev. B, 1986, vol. 34, pp. 823-36.

16. J. Ćížek, I. Procházka, J. Kočík, and E. Keilová: Phys. Status Solidi A, 2000, vol. 178, pp. 651-62.

17. Y.Z. Chen, G. Csiszár, J. Cížžek, C. Borchers, T. Ungár, S. Goto, and R. Kirchheim: Scr. Mater., 2011, vol. 64, pp. 390-93.

18. J. Cížek, M. Janeček, T. Krajňák, J. Stráská, P. Hruška, J. Gubicza, and H.S. Kim: Acta Mater., 2016, vol. 105, pp. 258-72.

19. L.C. Smedskjaer, M. Manninen, and M.J. Fluss: J. Phys. F. Met. Phys., 1980, vol. 10, pp. 2237-49.

20. C. Hidalgo, G. Donzáles-Doncel, S. Linderoth, and J.S. Juan: Phys. Rev. B, 1992, vol. 45, pp. 7017-21.

21. F. Tuomisto and I. Makkonen: Rev. Mod. Phys., 2013, vol. 85, pp. $1583-1631$

22. X.S. Guan, Z.F. Dong, and D.Y. Li: Nanotechnology, 2005, vol. 16 , pp. 2963-71.

23. D.Y. Li, L. Wang, and W. Li: Mater. Sci. Eng. A, 2004, vol. 384, pp. $355-60$

24. W.H. Smith: Report No. KCP-613-5471, Allied Signal Aerospace Inc., Kansas City Division, August 1994. https://www.osti.gov/se rvlets/purl/10181340.

25. D. Raabe: in Physical Metallurgy, 5th ed., Elsevier, New York, 2014, pp. 2291-97.

26. A.G. Guy: Elements of Physical Metallurgy, 2nd ed., Addison-Wesley Publishing, Massachusetts, 1959, p. 422.

27. F.J. Humphreys and M. Hatherly: Recrystallization and Related Annealing Phenomena, 2nd ed., Elsevier, Oxford, 2004, pp. 196-213.

28. A. Yabuuchi, M. Maekawa, and A. Kawasuso: J. Nucl. Mater., 2011, vol. 419, pp. 9-14.

29. J. Dryzek, M. Wróbel, and E. Dryzek: Phys. Stat. Sol. B, 2016, vol. 253 , pp. 2031-42.

30. P. Horodek, K. Siemek, J. Dryzek, and M. Wróbel: Materials, 2017, vol. 10, pp. 1343-58.

31. F. Börner, S. Eichler, A. Polity, R. Krause-Rehberg, R. Hammer, and M. Jurisch: J. Appl. Phys., 1998, vol. 84, pp. 225562 .

32. A. Vehanen, P. Hautojarvi, J. Johansson, J. Yli-Kauppila, and P. Moser: Phys. Rev. B, 1982, vol. 25, pp. 762-80. 